\title{
O PROGRAMA INSTITUCIONAL DE BOLSAS DE INICIAÇÃO À DOCÊNCIA (PIBID) COMO POLÍTICA EDUCACIONAL PARA A CONSTRUÇÃO DA IDENTIDADE PROFISSIONAL DOS PROFESSORES DE GEOGRAFIA
}

\author{
THE INSTITUTIONAL PROGRAM OF TEACHING INITIATION BAGS \\ (PIBID) AS AN EDUCATIONAL POLICY FOR THE CONSTRUCTION OF \\ THE PROFESSIONAL IDENTITY OF TEACHERS OF GEOGRAPHY
}

\begin{abstract}
Josias Ivanildo Flores de Carvalho ${ }^{1}$ Francisco Kennedy Silva dos Santos ${ }^{2}$ Laryssa de Aragão Sousa ${ }^{3}$

\section{Resumo}

O objetivo desse estudo foi apresentar as possíveis contribuições do Programa Institucional de Bolsas de Iniciação à Docência (PIBID), mais especificamente como Política Educacional para a construção da Identidade Profissional Docente dos Professores de Geografia. . Portanto, optou-se pela pesquisa qualitativa de cunho bibliográfico visto que o fenômeno aqui apresentado dificilmente pode ser quantificado (MINAYO, 2009), realizando um mergulho teórico e documental, na tentativa de discutir com os autores a presente temática. Compreendese que as Políticas de Formação como o PIBID quando bem desenhadas possibilitam uma valorização da classe e uma reconstrução da identidade profissional dos Licenciados em Geografia e das demais Licenciaturas.
\end{abstract}

Palavras-chave: Formação de Professores. Geografia. Identidade Profissional. PIBID. Políticas Educacionais.

\begin{abstract}
The objective of this study was to present the possible contributions of the Institutional Program of Initiation Scholarship to Teaching (PIBID), more specifically as Educational Policy for the construction of the Professional Identity of Teachers of Geography Teachers. Therefore, we opted for the qualitative research of a bibliographic character since the phenomenon presented here can hardly be quantified (MINAYO, 2009), performing a theoretical and documentary dive, in an attempt to discuss with the authors the present theme. It is understood that the Training Policies such as the PIBID when well-designed allows a valuation of the class and a
\end{abstract}

\footnotetext{
${ }^{1}$ Mestrando do Programa de Pós-Graduação em Geografia da Universidade Federal de Pernambuco UFPE; colaborador do Grupo de Pesquisa Educação Geográfica, Cultura Escolar e Inovação (GPECI/CNPQ/UFPE); Membro do Laboratório de Ensino de Geografia e Profissionalização Docente LEGEP/UFPE e Bolsista do CNPq. E-mail de contato: josias-ivanildo@ hotmail.com

${ }^{2}$ Docente do Departamento de Ciências Geográficas da Universidade Federal de Pernambuco - UFPE; Coordenador do Programa de Pós-Graduação em Geografia - PPGEO/UFPE; Coordenador de Área do PIBID-Geografia/UFPE; Líder do Grupo de Pesquisa Educação Geográfica, Cultura Escolar e Inovação (GPECI/CNPQ/UFPE) e do Laboratório de Ensino de Geografia e Profissionalização Docente LEGEP/UFPE. E-mail de contato: kennedyufpe@gmail.com

${ }^{3}$ Graduanda do Curso em Licenciatura em Geografia pelo Departamento de Ciências Geográficas da Universidade Federal de Pernambuco - UFPE; Bolsista do Programa Institucional de Bolsa de Iniciação à Docência - PIBID/CAPES-MEC e membra do Laboratório de Ensino de Geografia e Profissionalização Docente-LEGEP/UFPE. E-mail de Contato: larivuska.a.s@ hotmail.com
} 
reconstruction of the professional identity of the Graduates in Geography and of the other Undergraduate degrees.

Keywords: Teacher Education. Geography. Professional Identity. PIBID. Educational Policies.

\section{INTRODUÇÃO}

Para que o Brasil avance na formação de professores bem qualificados para atuarem na Educação Básica se fazem necessário à implementação de políticas que valorizem a docência, no que diz respeitos as condições de acolhimento dos licenciandos, para a construção de uma identidade profissional e de capacidades cognitivas acadêmicas, visto que a profissão docente no Brasil, na maioria dos países da América Latina e na Europa sofreu um processo de sucateamento, conduzindo ao desgaste da profissão diante da estrutura social, mesmo que os governantes e a sociedade considerem a educação e os professores essenciais para o avanço econômico e intelectual das nações.

Assim, este artigo pretende apresentar as possíveis contribuições do Programa Institucional de Bolsa de Iniciação à Docência (PIBID), mais especificamente como política educacional para a construção da identidade profissional docente dos professores de geografia. Portanto, optou-se pela pesquisa qualitativa de cunho bibliográfico visto que o fenômeno aqui apresentado dificilmente pode ser quantificado (MINAYO, 2009), realizando um mergulho teórico e documental, na tentativa de discutir com os autores a presente temática.

Trabalhar com a Identidade Profissional dos Professores de Geografia é uma tentativa de revalorização desses profissionais na reconstrução de sua função social para o desenvolvimento da educação brasileira que contempla as Ciências Geográficas, pois a compreensão dos fenômenos geográficos que envolvem a sociedade e a natureza devem ser lecionados no ambiente escolar pelos licenciados em geografia que durante 30 anos tiveram sua formação prejudicada e consequentemente o ensino desta disciplina; que durante este período foi lecionada por indivíduos sem formação na área e quando possuíam formação específica, esta foi realizada de maneira sucateada, como por exemplo, a aprovação da Lei da Reforma do Ensino n ${ }^{\circ} 5.692 / 71$ que estabeleceu o 
modelo de licenciaturas polivalentes em todas as áreas, Pontuschka, Paganelli e Cacete (2009), levando a descaracterização dessa licenciatura e de outras.

Para tentar entender como se forma uma identidade profissional docente o que engloba os professores de geografia, irar-se-á utilizar alguns apontamentos de Bauman (2005), Santos (2011), Braga (2001), Cruz e Aguiar (2011) que já abordaram estudos sobre as problemáticas de identidade, profissionalização docente, identidades sociais, entre outros temas. Ressalta-se que não se busca definir um conceito de identidade profissional docente dos professores de Geografia ou da classe docente em geral, mas apontar como uma política educacional para a formação inicial e contínua dos professores poderá contribuir na valorização social dos professores e na reconstrução de sua própria identidade profissional no âmbito social.

A professora e pesquisadora Marli André (2012) é uma das defensoras do PIBID, ela já avaliou o programa e aponta o mesmo como um dos caminhos para a melhoria da educação básica e para o fortalecimento do magistério no Brasil. É a citada autora também que aproxima a importância de estudos que abordem a formação de professores e as políticas públicas, posto que são poucos os estudos que contemplam essa união, a mesma fez um estudo em 2013 que comprova tal afirmativa: "no período de 1999 a 2003, de um total de 1.184 pesquisas, apenas 53 (4\%) se voltaram para esse tema" (ANDRÉ, 2013, p. 37).

As pesquisas que envolvem a Educação e as Políticas Públicas para a formação dos professores é também recente nos programas de Pós-Graduação em Geografia, posto que as pesquisas para a Geografia estiveram voltadas para os conhecimentos específicos que compõe as Ciências Geográficas, como: a Geomorfologia, a Climatologia, a Geografia Urbana, a Geografia Econômica e dos Serviços, entre outras áreas que formam a Geografia. Os estudos sobre a formação de professores, a didática, o ensino e aprendizagem, etc., foram sempre destinados para a pedagogia, porém com o auxílio da mesma tenta-se aprofundar os questionamentos desses fatos para a melhoria do ensino de Geografia e da formação de professores para atuarem na Educação Básica.

\section{O Programa Institucional de bolsas de Iniciação à Docência (PIBID) como política educacional na formação de professores}

A criação do programa Institucional de Bolsas de Iniciação à Docência (PIBID) tem como um dos seus objetivos centrais aperfeiçoar e valorizar a formação de 
professores para a Educação Básica (CAPES, 2017), uma vez que durante a história das políticas educacionais não houve um esforço coletivo por parte do Governo Federal, Estaduais, Municipais e Distrital para incentivar a formação dos educadores para atuarem na profissão.

O programa PIBID foi lançado oficialmente no ano de 2007, por meio da fundação de Coordenação de Pessoal de Nível Superior (CAPES), ligada ao Ministério da Educação (MEC), que até o presente ano só desenvolvia atividades voltadas para a formação de pós-graduandos stricto sensu (mestrado e doutorado) que iriam atuar no Nível Superior em universidades públicas e privadas com e sem fins financeiros. Inicialmente o PIBID foi desenvolvido para atender a demanda dos licenciandos das instituições federais das áreas de exatas e das ciências da natureza: Química, Física, Biologia e Matemática, disciplinas essas que sofrem com a falta de professores nas escolas de Ensino Médio.

Esta medida ficou conhecida como nova CAPES por meio da Lei $n^{\circ}$ 11.502/2007 e o decreto $\mathrm{n}^{\circ}$ 6755, de 29 de janeiro de 2009 que institui a Política Nacional de Formação de Profissionais do Magistério da Educação Básica, que a partir dessas datas irão criar diversos programas, por exemplo, o PIBID, o Programa de Formação Inicial e Continuada, Presencial e a Distância, de Professores para a Educação Básica (PARFOR), entre outros; que conduziram a CAPES a atuar no fortalecimento da formação de professores para a Educação Básica, na modalidade inicial e contínua.

No entanto, era essencial a expansão do PIBID para todas as licenciaturas por meio da inclusão dos cursos das áreas de Ciências Humanas, Ciências Sociais, Artes e linguagens, posto que o PIBID busca fortalecer as licenciaturas e a profissão do magistério e não fazia sentido a não presença dessas áreas nos editais do PIBID/CAPES. Então em 2009 por meio do Edital de n02/2009, são incluídas todas as áreas do conhecimento, também todos os Níveis da Educação Básica, e as universidades estaduais, municipais e particulares sem fins financeiros no programa.

No ano de 2010 houve a adoção de um novo decreto $\mathrm{n}^{\circ} 7.415$, de 30 de dezembro que revogou o primeiro de 2009, sendo feitas algumas alterações; em 2016 foi adotado o decreto $n^{\circ} 8.752$, de 9 de maio que estabeleceu novos objetivos e normas afim de organizar as Políticas de Formação de Professores para a Educação Básica, dando continuidade ao PIBID e outros programas visto que o objetivo era fortalecer a Política Nacional de Formação de Professores para a Educação Básica, diante da 
demanda que a classe profissional docente necessitava/necessita, posto que existia/existe um alto índice de professores sem nível superior lecionando nas escolas e outros que lecionam disciplinas que não são da sua formação original, além do desprestígio com a classe oriundo do cenário socioeconômico que vivem os docentes que atuam na Educação Básica.

Alterações foram feitas posteriormente para a consolidação da Política Nacional de Formação de Professores para a Educação Básica por meio da Lei de Diretrizes e Bases da Educação Nacional (LDBEN) n 9.394 de dezembro de 1996, como por exemplo, a Lei $n^{\circ}$ 12.796, de 2013 que estabeleceu a inclusão do PIBID no inciso $5^{\circ}$ da LDBEN do capítulo VI apresentado a seguir:

$\S 5^{\circ}$ A União, o Distrito Federal, os Estados e os Municípios incentivarão a formação de profissionais do magistério para atuar na educação básica pública mediante programa institucional de bolsa de iniciação à docência a estudantes matriculados em cursos de licenciatura, de graduação plena, nas instituições de educação superior. (Incluído pela Lei no 12.796, de 2013). (BRASIL, 2013).

Destaca-se que a formação dos profissionais do magistério não é mais limitada a esfera da União, mas também dos Estados Federativos, do Distrito Federal e dos Municípios. Existindo assim, uma rede nacional legal voltada para a formação dos professores que redesenhe as políticas e os projetos para o melhoramento da formação dos professores e para o avanço na qualidade de ensino da Educação Básica no âmbito nacional.

Assim, a CAPES estabeleceu os seguintes objetivos para o PIBID desenvolver suas atividades no âmbito acadêmico e escolar:

1. Incentivar a formação de docentes em nível superior para a educação básica; 2. Contribuir para a valorização do magistério; 3. Elevar a qualidade da formação inicial de professores nos cursos de licenciatura, promovendo a integração entre educação superior e educação básica;4. Inserir os licenciandos no cotidiano de escolas da rede pública de educação, proporcionando-lhes oportunidades de criação e participação em experiências metodológicas, tecnológicas e práticas docentes de caráter inovador e interdisciplinar que busquem a superação de problemas identificados no processo de ensinoaprendizagem;5. Incentivar escolas públicas de educação básica, mobilizando seus professores como coformadores dos futuros docentes e tornando-as protagonistas nos processos de formação inicial para o magistério; e 6. Contribuir para a articulação entre teoria e prática necessárias à formação dos docentes, elevando a qualidade das ações acadêmicas nos cursos de licenciatura. (BRASIL, 2007). 
Tais objetivos dialogam com os estabelecidos na LDBEN de 1996 que no título VI trata dos profissionais da educação em seu parágrafo único abordando os fundamentos necessários para o exercício da atividade profissional da educação na Educação Básica:

Parágrafo único. A formação dos profissionais da educação, de modo a atender às especificidades do exercício de suas atividades, bem como aos objetivos das diferentes etapas e modalidades da educação básica, terá como fundamentos: (Incluído pela Lei $\mathrm{n}^{\circ} 12.014$, de 2009); I - a presença de sólida formação básica, que propicie o conhecimento dos fundamentos científicos e sociais de suas competências de trabalho; (Incluído pela Lei no 12.014, de 2009); II - a associação entre teorias e práticas, mediante estágios supervisionados e capacitação em serviço; (Incluído pela Lei $\mathrm{n}^{\circ}$ 12.014, de 2009); III - o aproveitamento da formação e experiências anteriores, em instituições de ensino e em outras atividades. (Incluído pela Lei nº 12.014, de 2009). (BRASIL, 2009).

Dado que ainda persiste a dicotomia teoria e prática no momento de transformar os conhecimentos teóricos adquiridos nos cursos na prática docente nas escolas para que possam alavancar o nível da educação com qualidade, além de aproximar os cursos de licenciatura das escolas, visto que a maioria dos estágios de docência não vem conseguindo aliar teoria e prática e nem inovar nas práticas, etc. Como relatado a seguir:

Pior ainda, não se exerce a medicina sem um estágio de "residência", onde efetivamente se aprende o exercício realista e concreto da profissão, enquanto que para a maior parte dos alunos que buscam ser professores raramente se cobram estágios e, se a exigência se impõe, todos sabemos com que facilidade é a mesma escamoteada. (SELBACH, et al. 2014, p. 7).

Porém, o PIBID não vem substituir os estágios que continuam e devem compor a grade curricular dos cursos de licenciatura, dado que quando bem executados pelos professores responsáveis, pelos licenciandos e em parceira com as escolas contribuem significativamente na formação dos professores como acontecem com os estágios de residência dos cursos de medicina.

Assim, para conceber a Política Nacional de Formação de Professores para a Educação Básica o que inclui o PIBID se faz necessário a recursos financeiros e incentivos tanto para os licenciandos, como para os licenciados que já atuam na 
educação básica e para os professores formadores das instituições superiores de ensino. A Capes então estabeleceu cinco modalidades de bolsas para os participantes do PIBID:

\begin{abstract}
A Capes concede cinco modalidades de bolsa aos participantes do projeto institucional:1. Iniciação à docência - para estudantes de licenciatura das áreas abrangidas pelo subprojeto. Valor: $\mathrm{R} \$ 400,00$ (quatrocentos reais). 2. Supervisão - para professores de escolas públicas de educação básica que supervisionam, no mínimo, cinco e, no máximo, dez bolsistas da licenciatura. Valor: $\mathrm{R} \$ 765,00$ (setecentos e sessenta e cinco reais). 3. Coordenação de área - para professores da licenciatura que coordenam subprojetos. Valor: $\mathrm{R} \$ 1.400,00$ (um mil e quatrocentos reais). 4. Coordenação de área de gestão de processos educacionais - para o professor da licenciatura que auxilia na gestão do projeto na IES. Valor: $\mathrm{R} \$ 1.400,00$ (um mil e quatrocentos reais). 5. Coordenação institucional - para o professor da licenciatura que coordena o projeto Pibid na IES. Permitida a concessão de uma bolsa por projeto institucional. Valor: $\mathrm{R} \$ 1.500,00$ (um mil e quinhentos reais). As bolsas são pagas pela Capes diretamente aos bolsistas, por meio de crédito bancário. (BRASIL, 2017).
\end{abstract}

A CAPES também oferece às instituições que participam do PIBID, tanto as públicas quanto as sem fins lucrativos, recursos financeiros para o desenvolvimento dos projetos institucionais de cada instituição superior de ensino (IES) para aquisição de materiais de consumo que serão utilizados pelos subprojetos de todas as licenciaturas nas escolas que possuem o PIBID, como constatado no site da CAPES (2017). Nota-se que para o desenvolvimento da educação básica e da formação de professores inicial e contínua se faz extremamente necessário à destinação de recursos e de programas que incentivem a docência.

Com abertura do programa PIBID para os cursos de humanas as licenciaturas em Geografia de várias instituições puderam solicitar a participação no programa devido às contribuições significativas para o fortalecimento da formação dos licenciandos que conduzem a uma reafirmação na identidade profissional docente dos futuros professores de Geografia e também das outras licenciaturas.

\title{
3. A construção da identidade profissional dos professores de Geografia a partir do PIBID
}

Ao abordamos a identidade profissional dos professores de geografia a partir do PIBID surge a seguinte pergunta: como se constrói uma identidade? E para responder essa questão temos que entender que enquanto sujeitos que naturalmente necessitamos

Revista de Administração Educacional, Recife, V. 1. No 2 -jul/dez. 2017 p. 21-36 
viver em coletividade criamos laços afetivos (família, amigos, igreja, etc.), e/ou profissionais (classe médica, advogados, professores, instituições organizadoras de profissões, etc.); assim necessita-se de uma conjuntura social para que se possa sentir parte de um grupo social, Cruz e Aguiar (2011) a partir dos estudos de Tardif (1983) abordam o conceito de identidade da seguinte maneira:

[...] o conceito de identidade como o reconhecimento de filiação do sujeito a um ou a vários grupos, junto com o significado emocional e de valorização ligado a essa filiação que envolve processos socioafetivos, cognitivos e valorativos que são implicados na organização singular do sujeito em interação com o ambiente social (TADJFEL, 1983 apud CRUZ e AGUIAR, 2011, p. 77-78).

Seguindo o exposto pelas autoras pode-se então compreender que para a construção de uma identidade profissional com relação aos professores de Geografia se faz também necessário uma valorização profissional por parte não apenas dos sujeitos que compõem os docentes de Geografia, mas também pela a sociedade geral, pois como verificado em Cruz e Aguiar (2011), existe a necessidade de uma organização social do sujeito e sua interação com o ambiente social.

Um dos importantes pensadores sobre a identidade Bauman (2005) aborda o pertencimento e a identidade como algo não sólido e que não existe uma garantia para toda vida sobre o pertencimento, devido às rupturas sociais e emocionais que os indivíduos possam viver ou que já viveram, porém estão em constante construção de suas identidades pessoal, social e profissional posto que iremos desenvolver ao longo da vida várias tarefas em sociedade e individualmente, assim o autor aponta:

Tornamo-nos conscientes de que o "pertencimento" e a "identidade" não tem a solidez de uma rocha, não são garantidos para toda a vida, são bastante negociáveis e revogáveis, e de que as decisões que o próprio indivíduo toma, os caminhos que percorre, a maneira como age - e a determinação de se manter firme a tudo isso - são fatores cruciais tanto para o "pertencimento" quanto para a "identidade". Em outras palavras, a ideia de "ter uma identidade" não vai ocorrer às pessoas enquanto o "pertencimento" continuar sendo o seu destino, uma condição sem alternativas. Só começaremos a ter ideia na forma de uma tarefa a ser realizada, e realizada vezes e vezes sem conta, e não de uma só tacada. (BAUMAN, 2005, p, 17-18).

Para Bauman (2005), a questão dos estudos sobre a identidade é um desafio para a sociologia, posto que há algumas décadas atrás, os estudos sobre a identidade não estavam no centro dos debates da sociedade, ficando unicamente como objeto de 
mediação filosófica segundo o autor. Porém, a identidade no presente momento está nas discussões e nos estudos das diversas áreas não só na Filosofia ou na Sociologia, mas também na Educação, Geografia, etc., fato este que advêm das problemáticas que o mundo líquido (globalizado) vem interferindo na construção das identidades pessoais e coletivas, como também nas relações de trabalho e nas profissões.

As profissões e a identidade pessoal e profissional são conceitos e discursões que dialogam para o entendimento de como se organizam as profissões, a construção de pertencimento ou de não pertencimento ao grupo social, assim para entender um pouco mais da identidade docente e da profissionalização docente necessita-se discorrer sobre essas temáticas que são dinâmicos.

Segundo Santos (2011), em seu livro: profissões e identidades profissionais o funcionalismo pertencente ao corpo teórico da sociologia das profissões como movimento anterior aos anos 70 do século $\mathrm{XX}$, destacando também que as questões voltadas para os estudos ou formação da concepção de profissões remontam do século XVII e sua sistematização no início do século XX. A autora aponta que muito dos pensadores do movimento funcionalista abordavam a organização institucional e o papel dos homens no mundo do trabalho, ou seja, a autora aponta que essa corrente entendia que o sujeito e o objeto eram de um único sistema social. Santos $(2011$, p. 11) ressalta que os aspectos funcionalistas para caracterizar uma profissão tinham que essencialmente possuir: "uma comunidade relativamente homogénea onde os membros partilham identidades, valores, definições de papéis e de interesses. Existem, todavia, diferentes pontos de vista dentro da abordagem funcionalista de profissões". Assim, compreende-se que existem ideias centrais para se abordar as profissões, porém não existe um conceito fechado como também o conceito de identidade.

Santos (2011), em seu livro apresenta a corrente interacionista, que contrária a funcionalista que privilegia os aspectos formais e organizacionais da institucionalização da profissão. O interacionismo é apresentado pela autora a partir do conhecimento identitário da profissão defendida por autores como Dubar e Triper (1998) citados por Santos em seu estudo. Sendo assim, não existe uma preocupação de categorização da profissão, e sim uma análise e uma compreensão dos motivos que conduzem um sujeito ou um grupo de indivíduos e seus condicionantes, que levam a emergência de institucionalização de uma profissão. Essa maneira em compreender a profissão é recentemente nova se compararmos com o funcionalismo. 
Ao apontar duas concepções sobre as profissões Santos (2001) permite-nos entender que existe uma diversidade de correntes que abordam as identidades profissionais e profissões, nos fundamentos teóricos contemplados pela autora existem semelhanças e contradições pelos pesquisadores que se dispõem a pesquisar esses fenômenos como toda corrente científica. Santos (2001) enfatiza que a construção da identidade parte do individual para o coletivo como também pode ocorrer ao contrário (do coletivo para o individual), então compreendemos que para a construção da identidade pessoal docente e da profissionalização docente enquanto classe faz-se necessário a organização em grupos e instituições profissionais legais, visto que são necessários para legitimação perante a sociedade e as instituições governamentais que regulamentam atividades profissionais, como também os aspectos individuais de cada grupo e do próprio individuo que compõe uma profissão.

Santos (2011) em seus estudos esclarece-nos que assim como a identidade as profissões possuem um diferencial, ou seja, é única entre as muitas profissões que existem no mundo social, no entanto não estão separadas no espaço, suas bases ideológicas, sociais, culturais, individuais pode-se dizer estão ligadas diretamente já que possuem função e significado social que as validam.

Assim, começamos a problematizar a questão da docência em Geografia em um contexto de uma profissão voltada para a Educação Básica, mais especificamente o Ensino Fundamental II que compreende do $6^{\circ}$ ano ao $9^{\circ}$ ano e do Ensino Médio que está organizado do $1^{\circ}$ ano ao $3^{\circ}$ ano, tal que os Cursos de Geografia que possuem Licenciaturas habilitam os licenciandos para atuarem exclusivamente com esses anos. Esclarecido isto, pode-se avançar na problemática que perpassa a profissão de ser professor para atuar na educação básica das escolas brasileiras, uma vez que é na educação básica que se encontram a maioria dos professores de Geografia nas instituições públicas e privadas com e sem fins financeiros.

Os professores da Educação Básica estão diante de um meio profissional complexo desde o século XX e que vem passando por grandes transformações no que diz respeito às condições de trabalho, com uma enorme desvalorização salarial para as atividades que desempenham e um grande desprestígio por parte dos representantes públicos, da sociedade civil e até pelo próprio público que atende.

De maneira mais específica, a Geografia que compõe o campo das Ciências Humanas muitas vezes é mal compreendida no que diz respeito aos seus saberes e de seus objetivos e utilidade para a sociedade, visto que durante o desenvolvimento desta 
ciência houve uma divisão da Geografia Acadêmica e da Geografia Escolar, nas universidades existia uma pluralidade de correntes epistemológicas, da utilização de métodos e práticas de ensino diversificadas, já nas escolas houve um ensino memorativo, muitas vezes descontextualizado da realidade dos discentes e professores que não possuíram uma boa formação. (CASTELLAR, 2014). Reflexo de políticas educacionais adotadas nos anos 60, 70 e 80 do século XX para a formação e o ensino de Geografia que não valorizam os docentes e nem o ensino.

A formação dos professores de Geografia e da classe docente não obteve muito sucesso no que diz respeito a uma formação sólida, que envolva a União, os Estados, o Distrito Federal e os Munícipios devido a uma política de formação fragmentada que perdurou até o inicio do século XXI. Ao contrário dos cursos mais tradicionais como a Medicina e o curso de Direito (que pertencem a corrente funcionalista das profissões) que desde sua concepção sempre obtiveram prestígio social e reconhecimento financeiro, considerados como profissões da elite, com estágios de residência para que os médicos iniciassem sua profissão e que posteriormente iriam atuar em hospitais, os advogados encontravam no início da carreira, escritórios de advocacia, tribunais de justiça que contribuíam na boa formação dos mesmos. Estamos tratando dos cursos funcionalistas que detinham o status social e legal de únicas profissões diante das demais atividades realizadas, como o caso da docência que envolve todas as licenciaturas e áreas do conhecimento.

Devido a real necessidade de um programa para a valorização do magistério da educação básica, foi criado o Programa Institucional de Bolsa de Iniciação à Docência (PIBID), programa que há 10 anos vem tentando redesenhar o significado da docência para os licenciandos das instituições de ensino superior que o possuem. O programa é essencial para devolver nos professores iniciantes autoconfiança, habilidades cognitivas e ligação profissional, visto que o programa permite aos licenciandos participar das atividades escolares e trocar experiências profissionais sobre a prática dos docentes adotadas, entre outros.

Desta maneira, o programa vem atender uma reivindicação da classe docente no que diz respeito à formação dos professores para a Educação Básica como também as propostas sugeridas por especialistas da educação, a exemplo, de Fátima Braga (2001) que desenvolveu sua dissertação sobre a formação de professores e a identidade profissional desses sujeitos, a mesma constatou que é necessária a aplicação de programas para o fortalecimento da classe docente e também para a reconstrução da 
identidade profissional dos docentes, posto que diante do extremo estresse profissional e péssimas condições de trabalho que conduziram a experiências traumáticas para muitos professores iniciantes, que conduza perda dos laços afetivos e identitários para com a profissão, assim ela destaca:

\begin{abstract}
queremos com isto defender a necessidade de um programa sistemático e combinado entre a escola e a faculdade, que facilite a consecução do desenvolvimento pessoal, profissional e social do profissional em formação. Os orientadores das escolas precisam de conhecer os pontos de contato entre as experiências que a prática faculta aos estagiários e as perspectivas apresentadas na faculdade, do mesmo modo que esta se deve interessar pelos desafios que os professores principiantes enfrentam no quotidiano, para assim os consciencializar das suas opções. (BRAGA, 2001, p. 128).
\end{abstract}

Entende-se que para o movimento de formação inicial dos professores (Geografia), deve-se existir um meio social que conduza aos profissionais o sentimento de pertencimento ao ambiente de trabalho e da estrutura organizacional como um todo, pois nenhuma profissão se auto sustenta em sua própria concepção ou grupo, mas também não sobrevive socialmente sem isto.

Os estudos de Scoz (2011) se debruçam sobre a questão da identidade e das subjetividades que os professores possuem e a reconstroem diariamente no ambiente de trabalho (escola) e no convívio social com os outros profissionais, para a autora a identidade e a subjetividade é algo dinâmico, complexo e processual. Sendo assim, entende-se que a formação dos professores de Geografia vem permeada de fenômenos positivos e negativos, porém a consciência do significado que os sujeitos dão a escolhas que fizeram pela docência aqui compreendendo a Geografia fará toda diferença na construção de sua identidade profissional e pessoal que serão levados para o momento de sua prática na docência.

Scoz (2011) destaca a importância da sociedade, das universidades e até dos professores se conceberem como um indivíduo pensante sobre os conteúdos que ensinam e sobre as práticas que desenvolvem na sala de aula. Posto que as fortes pressões que os professores sofrem pelo sistema regulamentador da educação conduzem o mesmo para a perda de identidade e de emoções para com a profissão escolhida, gerando um perigo para a educação como um todo, já que os professores devem estar motivados e dispostos a ensinar, aprender e a construir conhecimento no seu meio profissional. 
Essa concepção defendida por Scoz (2011) compõe um movimento científico universitário para que entendam os professores como sujeitos ativos e conscientes dos conhecimentos de suas ciências, sobre os métodos de ensino e aprendizagem, sobre as práticas desenvolvidas em sala de aula, e não como meros reprodutores do saber, o que também contribui para que a sociedade e até alguns professores se enxerguem como profissionais secundários, que sua profissão é um sacerdócio e por isso deve aceitar as péssimas condições de trabalho e salário, entre outros adjetivos que levam a desconstrução do valor social desses profissionais. Pimenta e Ghedin (2012) valorizam a questão da formação de professores reflexivos sobre sua profissão e sobre o cenário que a mesma se encontra, buscando avançar na consolidação de uma educação básica de qualidade que perpassa uma boa formação inicial e contínua.

Diante destes apontamentos pode-se ter noção que o conceito de identidade e de profissionalização docente é algo complexo que envolve diversas correntes do pensamento humano e que se fazem necessários estudos mais aprofundados para um maior entendimento da construção da identidade profissional docente dos professores de Geografia e das demais licenciaturas. No entanto, fica aqui a tentativa em avançar nos estudos que contemplam a formação de professores e das políticas públicas para educação, além da compreensão da identidade dos professores.

\section{ALGUMAS CONSIDERAÇÕES}

Neste trabalho não se buscou conceituar o que é Identidade e nem Profissionalização Docente, mas sim problematizar quais as noções que formam uma identidade profissional docente a partir de uma política de formação de professores para atuarem na educação básica pública. Destacando que quando existe uma política clara para o incentivo de novos professores poder-se-á com o apoio de escolas, dos docentes em exercício e das universidades poderemos ter um novo quadro de professores mais autoconfiantes sobre a escolha da profissão e reconstruindo sua identidade profissional perante a sociedade, entretanto esse fenômeno não se realiza de maneira isolada e muito menos apenas com as reivindicações da classe, visto que a educação é algo que envolve diretamente e indiretamente toda a sociedade.

A docência enquanto profissão é um processo contínuo e inacabado, que envolve os professores, pois são estes que contemplam a classe enquanto trabalhadores que exercem uma profissão fundamental para o desenvolvimento humano em suas áreas, 
econômicas, cultural, de meio ambiente e de formação de cidadãos pensantes e conscientes que agem sobre o mundo nas suas relações homem e natureza. Assim sendo a formação deve ser a mais completa possível que alie teoria e prática e que seu espaço de trabalho, assim a escola deve proporcionar um acolhimento pelos seus pares e pela a estrutura física escolar que desperte o prazer pela docência diariamente e continuamente.

As políticas de formação de professores devem se pautar na construção do fortalecimento dos profissionais do Magistério da Educação Básica para que erros cometidos no passado não voltem a se repetir ou que permaneçam imodificáveis por parte das instituições formadoras de professores e por parte do Ministério da Educação do Brasil, convém destacar que a Educação é um processo social e cabe a sociedade também exigir dos órgãos maiores incentivos para a valorização dos professores que sem dúvida alguma irá influenciar no ensino e no desenvolvimento intelectual dos alunos para a construção de um mundo melhor em tempos de globalização e de incertezas.

A criação do PIBID em 2007 pela CAPES e pelo MEC é uma tentativa de modificar a realidade dos cursos de formadores de professores e dos problemas encontrados pelos licenciandos no início da carreira, como a falta de valorização social, condições de trabalho e de estágio, que não permitem a criação de pertencimento à classe docente, como também os baixos salários e a sobrecarga de trabalho, aspectos estes que não contribuem na consolidação de uma identidade profissional docente em Geografia e nem em qualquer outra licenciatura desde o início e até as várias décadas da profissão docente.

Porém, nos anos de 2016 e 2017 o PIBID sofreu cortes orçamentários que afetaram diretamente os bolsistas do programa, como o corte de bolsas, corte na verba de custeio para a compra de materiais didáticos que são utilizados nas atividades desenvolvidas pelos Pibidianos junto aos alunos da Rede Básica de Ensino que possuem os subprojetos do PIBID. Estes acontecimentos afetam diretamente na Política de Formação de Professores para a Educação Básica desenhada desde 2007 e nas metas do Plano Nacional da Educação (PNE) que está em ação desde 2014 e tem a formação inicial e contínua dos professores também como foco diante do sucateamento da classe docente.

Diante dos últimos fatos aqui apresentados espera-se que a Política Nacional de Formação Docente para a Educação Básica seja fortalecida para que se possam formar 
no século XXI professores melhor qualificados e com maior pertencimento a classe profissional docente, dado que os meios de acesso e permanência dos professores quando bem executados e sendo prioridade pelo Estado surtirá efeitos, como é o caso do PIBID e dos programas em ação que estão contribuindo para o fortalecimento do sistema educacional brasileiro e para a formação dos docentes.

\section{REFERÊNCIAS}

ANDRÉ. M. Políticas e Programas de apoio aos Professores Iniciantes no Brasil. Cadernos de Pesquisa. V.42 n.145 p.112-129 jan./abr. 2012.

Formação de Professores: a constituição de um campo de estudos. Educar em Revista, Curitiba, Brasil, n. 50, p. 35-49, out./dez. 2013. Editora UFPR.

BAUMAN, Z. Identidade. Rio de Janeiro: Jorge Zahar Ed., 2015.

BRASIL. Ministério da Educação - MEC, Brasília, 2015. Brasília.

.Conselho Nacional de Educação - CNE, resolução $n^{\circ}$ 2, de $1^{\circ}$ de julho de 2015

Lei de Diretrizes e Bases da Educação Nacional: n 9394/96. Brasília, 1996.

Fundação Coordenação de Aperfeiçoamento de Pessoal de Nível Superior CAPES. Brasil, 2017.

Decreto $\mathbf{n}^{0} \mathbf{6 . 7 5 5}$, de 29 de janeiro de 2009, e Lei $\mathrm{n}^{\circ} 11.947$, de 16 de junho de 2009, no seu Art. 31.

Lei $\mathbf{n}^{\circ}$ 11. 502, de 11 de julho de 2007 que modifica as competências e a estrutura organizacional da Fundação Coordenação de Aperfeiçoamento de Pessoal de Nível Superior CAPES.

Plano Nacional de Educação (PNE). Lei no 13.005, de 25 de junho de 2014.

CRUZ, L. M. F. e AGUIAR, C. C. M. Trajetórias na identidade profissional docente: aproximações teóricas. Psic. da Ed., São Paulo, 33, $2^{\circ}$ sem. de 2011, pp. 7-22.

CAStellar, S. e VILHENA, J. Ensino de Geografia. São Paulo. Ed. Cengage Learning, 2014.

BRAGA, Fátima. Formação de Professores e Identidade Profissional. Coimbra. Ed. Quarteto Editora, 2001.

MINAYO, S. C. M. (Org) Pesquisa Social: teoria, método e criatividade. Petrópolis-RJ: Vozes, 2009.

PIMENTA. G. S. e GLEDIN. E. (org). Professor Reflexivo no Brasil: gênese e crítica de um conceito. $7^{\text {a }}$. Ed. São Paulo: Cortez, 2012. 
PONTUSChKA, N. N; PAgAnelli, I. T e CACETE, H. N. Para Ensinar e Aprender Geografia. $3^{\text {a }}$. Ed. - São Paulo: Cortez, 2009.

SANTOS, C. C. Profissões e Identidades Profissionais. Ed. Universidade de Coimbra. Coimbra. 2011.

SELBACH, et al. Geografia e Didática. 2. Ed.- Petrópolis, RJ: Vozes, 2014.

SCOZ, Beatriz. Identidade e Subjetividade de professores: sentidos do aprender e do ensinar. Petrópolis: Vozes. 2011. 